\title{
Therapeutic targets in the pancreatic adenocarcinoma microenvironment: past challenges and opportunities for the future
}

\author{
Erica S. Tsang, Margaret A. Tempero \\ Helen Diller Family Comprehensive Cancer Center, University of California San Francisco, San Francisco, CA 94158, USA. \\ Correspondence to: Dr. Margaret A. Tempero, Helen Diller Family Comprehensive Cancer Center, University of California San \\ Francisco, San Francisco, Box 3211, 550 16th Street, CA 94158, USA. E-mail: Margaret.Tempero@ucsf.edu
}

How to cite this article: Tsang ES, Tempero MA. Therapeutic targets in the pancreatic adenocarcinoma microenvironment: past challenges and opportunities for the future. J Cancer Metastasis Treat 2021;7:33.

https://dx.doi.org/10.20517/2394-4722.2021.22

Received: 27 Jan 2021 First Decision: 22 Feb 2021 Revised:1 Mar 2021 Accepted: 25 Mar 2021 Published: 23 Jun 2021

Academic Editors: J. H. Kleeff, Lucio Miele Copy Editor: Xi-Jun Chen Production Editor: Xi-Jun Chen

\begin{abstract}
Pancreatic ductal adenocarcinoma (PDAC) remains a leading cause of cancer-related mortality, with cytotoxic chemotherapy still the mainstay of treatment. Beyond effective therapeutic agents alone, successful drug delivery is paramount. In PDAC, the tumor microenvironment represents a physical barrier that limits in vivo drug delivery and efficacy. In this review, we highlight therapeutic targets in the tumor microenvironment, focusing on past challenges and opportunities for the future. Targets discussed include the Hedgehog pathway, angiogenesis, hyaluronic acid, cancer-associated fibroblasts and associated cytokines, among others. Despite the obstacles in successfully recapitulating promising lab results to practice-changing clinical results, many important lessons have been learned to improve clinical trial design within a highly engaged and motivated scientific community. These collaborative efforts and the collective optimism will continue to propel the momentum forward to overcome these barriers and ultimately improve patient outcomes.
\end{abstract}

Keywords: Pancreatic cancer, PDAC, tumor microenvironment, pancreatic stroma

\section{INTRODUCTION}

Pancreatic ductal adenocarcinoma (PDAC) represents a leading cause of cancer-related mortality, with a 5- 
year survival rate of $9 \%^{[1]}$. Cytotoxic chemotherapy remains the mainstay of treatment for patients with unresectable locally advanced and metastatic PDAC, with PARP inhibitors recently approved for the subgroup of patients with germline BRCA mutations ${ }^{[2,3]}$. Despite the advent of improved genomic sequencing and the recognition of specific molecular subtypes, direct therapeutic implications are still being investigated ${ }^{[4-8]}$.

Beyond effective therapeutic agents alone, successful drug delivery is paramount and in PDAC, the tumor microenvironment embodies a physical barrier that limits in vivo drug delivery and efficacy. The PDAC tumor microenvironment consists of a complex arrangement of extracellular matrix (ECM), vasculature, fibroblasts, stellate cells, and immune cells ${ }^{[6,9,10]}$. Pancreatic stellate cells (PSCs), which make up about half of the stroma, are activated by a number of mechanisms, including chronic inflammation, hypoxia-inducible factor 1-alpha (HIF1 $\alpha$ ), and molecular signaling pathways ${ }^{[11]}$. Once activated, PSCs drive desmoplasia by producing significant quantities of the ECM, such as collagen, hyaluronic acid (HA), fibronectin, and matrix metalloproteases. This desmoplastic reaction represents a cardinal feature in PDAC [Figure 1] $]^{[12,13]}$.

This dense ECM lends itself to high interstitial fluid pressure (IFP), hindering perfusion and preventing the successful delivery of chemotherapy through the stroma ${ }^{[14,15]}$. Stroma-specific subtypes have been described, with a "normal" subtype demonstrating high expression of PSC markers compared to the "activated" subtype consisting of macrophages and proinflammatory cytokines ${ }^{[6,9]}$. These subtypes play a role in the regulation of tissue tension and stiffness. Despite the hostile environment of the ECM, PDAC tumors seem to thrive within. Physical forces within this microenvironment, including hydrostatic pressure and tissue tension, appear to direct epithelial cell signaling and promote tumor progression ${ }^{[16]}$. Stress from the expanding tumor also leads to direct expression of vascular endothelial growth factor (VEGF) A and promotes hypoxia by physically compressing surrounding vasculature ${ }^{[17]}$. This hypoxic milieu promotes the epithelial to mesenchymal transition and further contributes to a favorable setting for PDAC growth.

While PSCs and cancer-associated fibroblasts (CAFs) were terms that were traditionally used interchangeably, recent studies have shown that CAFs actually comprise a heterogeneous population. CAFs not only play a role in the production of ECM proteins and soluble factors, but are also active in facilitating interaction with immune cells. Inflammatory CAFs (iCAFs) play an important role in immune regulation, and may contribute to the immunotherapeutic resistance seen in early trials. One such mechanism involves increased NF- $\mathrm{KB}$ signaling from iCAFs leading to the subsequent blockade of cytotoxic T cell infiltration ${ }^{[18]}$. Another mechanism involves IL-6 secretion from iCAFs, representing the production of another immunosuppressive cytokine within the tumor microenvironment ${ }^{[19]}$. There are also mesenchymal stem cell CAFs, acting through the CSF-1 receptor pathway to increase the accumulation of tumor-associated macrophages, which can also block T cell intratumoral infiltration ${ }^{[20,21]}$. Additionally, single cell RNA sequencing has delineated another distinct CAF subtype, antigen-presenting CAFs, characterizing yet another mechanism of influence within the immune environment of PDAC ${ }^{[22]}$.

KRAS mutations have been identified in $>90 \%$ of patients with $\mathrm{PDAC}^{[4]}$. The most common KRAS $S^{G 12 D}$ mutation has been demonstrated to up-regulate inflammatory pathways and stimulate stromal activation ${ }^{[23]}$. Genetically engineered mouse (GEM) models designed with various driver mutations resulted in differing amounts of stromal desmoplasia, highlighting the impact not only on tumor cell proliferation but also on the tumor microenvironment ${ }^{[24]}$. Furthermore, molecular profiling has elucidated stroma-specific subtypes, which have prognostic implications and are correlated with distinct immune infiltrates and biomarkers ${ }^{[0,9,25]}$. 


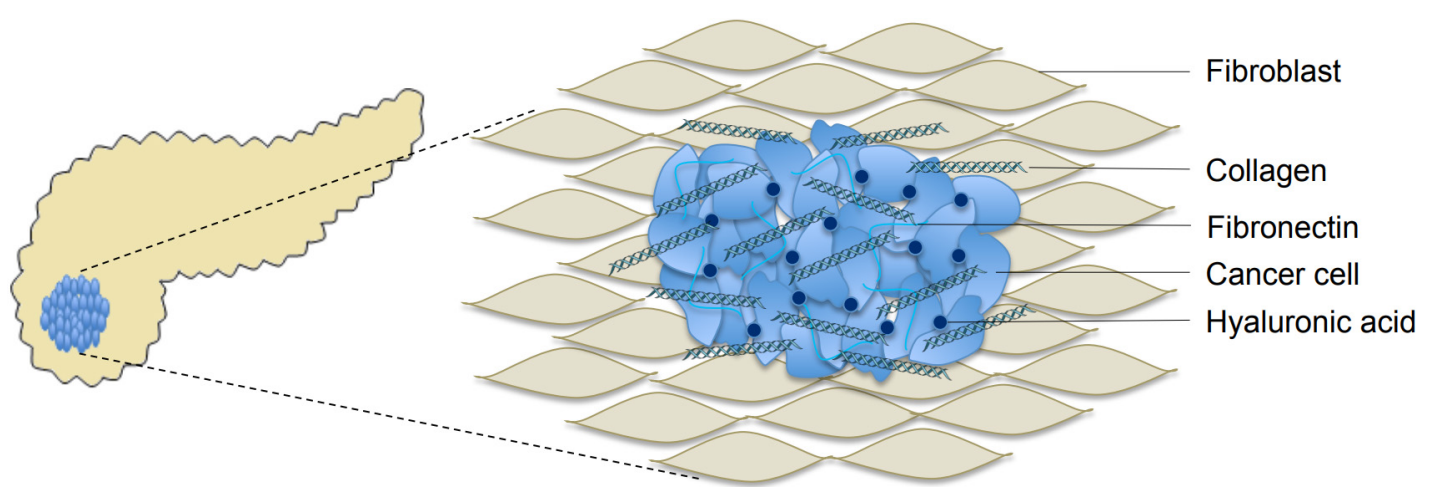

Figure 1. Schematic figure of the desmoplastic stromal reaction in PDAC involving fibroblasts, collagen, hyaluronic acid and extracellular matrix proteins (courtesy of Drs. A. Hosein, R. Brekken, and A. Maitra). PDAC: Pancreatic ductal adenocarcinoma.

In addition to the tumor microenvironment surrounding the PDAC primary, metastatic sites such as the liver also have their own microenvironment to create a pro-metastatic niche often with resultant chemoand immunotherapeutic resistance ${ }^{[26]}$. This pro-metastatic niche is defined by the presence of increased myeloid cells and matrix proteins, with involvement of hepatocytes, tissue inhibitor matrix metalloproteinase 1 , and tumor-derived exosomes ${ }^{[27-29]}$. Preclinical modeling has demonstrated that the presence of a liver metastasis triggers a systemic immune response mediated independently from programmed cell death protein $1(\mathrm{PD}-1)^{[30]}$. This provides additional mechanistic rationale for the challenges with immunotherapeutic resistance, particularly in the presence of liver metastases.

With an increased understanding of the biology of the tumor microenvironment, therapeutic agents targeting specific features and pathways of the stroma have been developed [Figure 2]. While immunotherapeutics are one of several exciting and upcoming strategies, an in-depth focus is beyond the scope of this manuscript. Here we review therapeutic targets in the tumor microenvironment focused on advanced PDAC, highlighting past challenges and opportunities for the future. Over the last several decades, there have been a plethora of clinical trials that failed to meet their primary endpoints; however, many important lessons have been learned to improve clinical trial design within a highly engaged and collaborative scientific community. The collective optimism and momentum remain high to overcome these barriers to ultimately improve patient outcomes.

\section{BREAKING DOWN THE BENCH TO BEDSIDE ADAGE}

The traditional bench to bedside model has proven successful in other malignancies, where promising results in the lab can be translated into practice-changing clinical trials that prolong survival and improve quality of life. Over the last several decades, we have learned that PDAC does not fall neatly into this mold where the dynamic in vivo tumor microenvironment interacts differently than expected based on preclinical models. One such example involves the hedgehog $(\mathrm{Hh})$ pathway, which is involved in the pathogenesis of $\mathrm{PDAC}^{[31-34]}$. The overexpression of Shh has been reported in more than $70 \%$ of primary tumors ${ }^{[3,35]}$. Within stromal cells, paracrine Hh signaling is reversed, leading to angiogenesis and contributing to the tumor microenvironment ${ }^{[36-38]}$. In an effort to overcome chemoresistance, Olive et al. ${ }^{[39]}$ administered gemcitabine with the Hh pathway inhibitor saridegib (IPI-926) to mice. They observed a subsequent increase in intratumoral gemcitabine concentration and stable disease. With this convincing preclinical evidence and scientific rationale for combination with chemotherapy, early phase clinical trials in patients with PDAC were launched. 


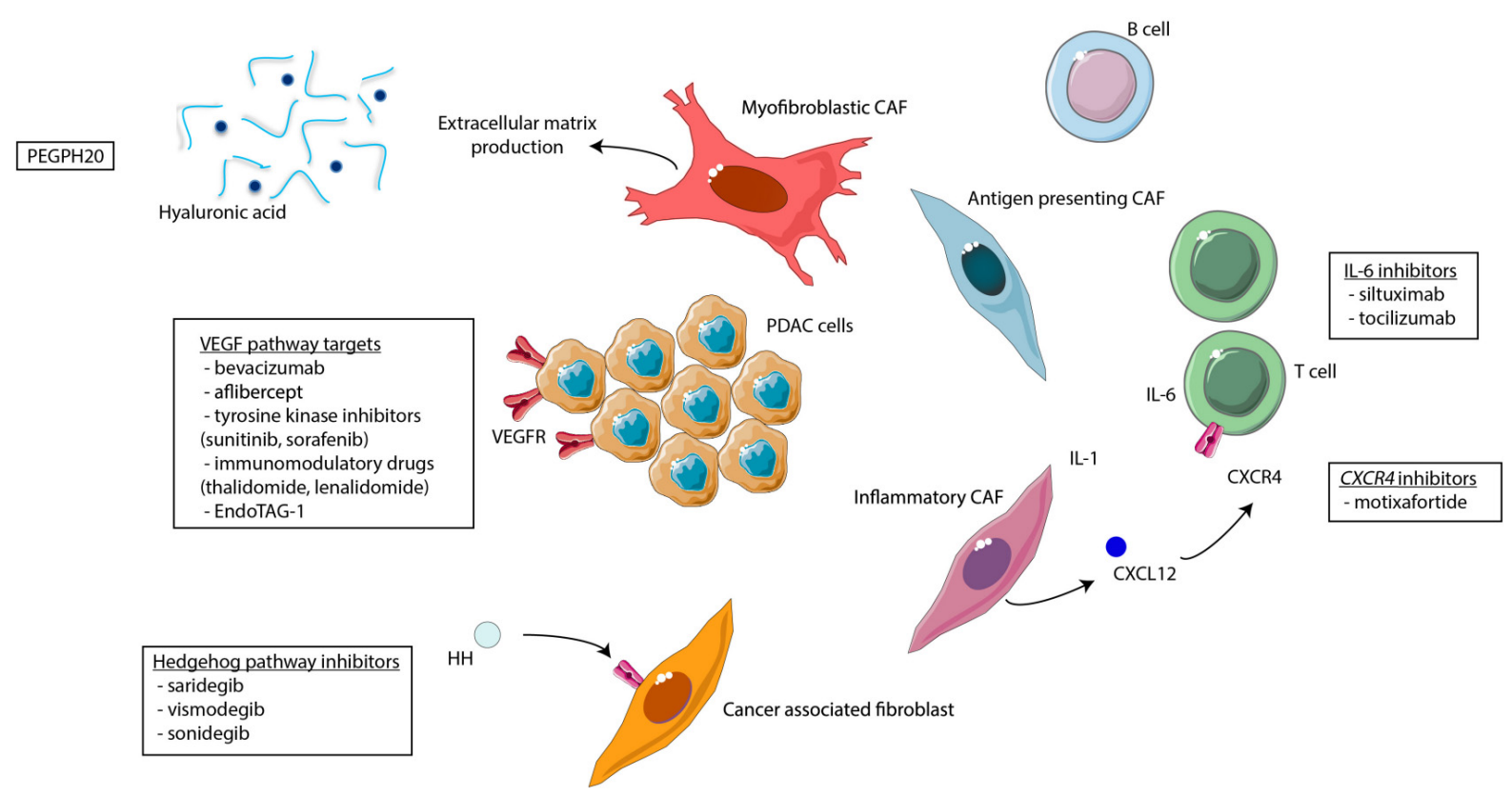

Figure 2. Schematic figure of select PDAC tumor microenvironment targets and therapeutic agents. HH: Hedgehog; CAF: cancerassociated fibroblast; PDAC: pancreatic ductal adenocarcinoma.

Saridegib was combined with gemcitabine in a phase $\mathrm{Ib}$ trial, demonstrating safety and tolerability ${ }^{[40,41]}$. However, the phase II portion of this combination was stopped after an interim analysis demonstrated a shorter median overall survival (OS) for the saridegib/gemcitabine arm compared to the placebo/gemcitabine arm. Saridegib was also studied with FOLFIRINOX in a phase I trial with a $67 \%$ objective response rate (ORR) in 15 patients, but this study was stopped early with the release of the interim phase II results of the saridegib and gemcitabine study ${ }^{[42]}$.

In one pilot study, Kim et al. ${ }^{[43]}$ enrolled 25 patients, $75 \%$ with elevated Shh expression at baseline biopsy, who received gemcitabine with vismodegib. Median progression-free survival (PFS) and OS measured 2.8 and 5.3 months, respectively. Correlative studies comparing the pre- and post-treatment PDAC cancer stem cells showed no significant difference with vismodegib treatment. In a separate study, Catenacci et al. ${ }^{[44]}$ investigated the combination of vismodegib with gemcitabine in a phase Ib/randomized phase II trial of unselected patients ( $n=106$ in phase II arm) with advanced PDAC. There was no difference in PFS or OS, and associated preclinical models did not demonstrate an improvement in drug delivery or efficacy with vismodegib. Vismodegib has also been studied in combination with gemcitabine and nab-paclitaxel where interim results were published in abstract form (59 patients of the planned sample size of 80 ), with median PFS of 5.5 months ${ }^{[45]}$. Final results have not yet been published.

A third Shh inhibitor sonidegib was investigated in combination with gemcitabine in a phase I study, with no clear clinical benefit and a median PFS similar to the current standard of care ${ }^{[46]}$. A second phase I trial of sonidegib, this time in combination with gemcitabine and nab-paclitaxel, has also been reported in abstract form demonstrating tolerability ${ }^{[47]}$. Given the disappointing results from combination Shh inhibitor and standard of care chemotherapy, the use of Shh inhibitors has not advanced to phase III trials or become incorporated into routine clinical care. 
Rather than simply moving onto the next target, understanding the mechanisms underlying this unsuccessful recapitulation from encouraging lab results to clinical trials was critical. Rhim et al. ${ }^{[48]}$ conducted experiments to genetically delete sonic Hh, resulting in decreased stromal desmoplasia. Paradoxically, this hastened tumor growth and metastasis, with increased mortality. One potential contributor to this paradoxical effect was the observation of increased vascularity and blood vessel density surrounding these undifferentiated tumors. Another important observation was that tumors with either genetically deleted Shh or post saridegib treatment were smaller in size but exhibited a more aggressive, undifferentiated histology. This may correlate with the clinical cachexia seen in patients with PDAC treated with a sonic $\mathrm{Hh}$ inhibitor. These observations highlight the value of appreciating the underlying complexity of the tumor stroma and provide insights into potential combinations that can be explored in the future. For example, rather than a one-size-fits-all approach, anti-angiogenesis targets could be considered as an adjunct for the subgroup of well-vascularized and poorly differentiated tumors.

In another study evaluating the discordant clinical results of Shh inhibitors, Lee et al.$^{[34]}$ reported that Hh pathway inhibition hastened growth, specifically impacting the epithelial and stromal element equilibrium. While stromal desmoplasia was suppressed, pancreatic intraepithelial neoplasia epithelium proliferated. By contrast, Hh pathway activation led to stromal hyperplasia and decreased epithelial growth, suggesting another therapeutic mechanism to be explored. A separate experiment examined the impact of unintended depletion of aSMA myofibroblasts by Shh inhibitors during stromal depletion, resulting in increased epithelial to mesenchymal transition and tumor proliferation ${ }^{[4]}$. Preclinical models demonstrated an immunosuppressive effect in the myofibroblast-depleted setting with anti-CTLA4 agents effectively decreasing tumor burden, thus representing yet another potential avenue for further study.

\section{DOES THE ANSWER LIE IN THE SEQUENCE?}

The bench to bedside model was also applied in studying angiogenesis targets in PDAC. VEGF expression was found to be associated with microvessel density (MVD), and high VEGF expression correlated with early recurrence post-resection ${ }^{[0,51]}$. Using mouse models injected with PDAC cells, Baker et al. ${ }^{[52]}$ demonstrated that chemotherapy with VEGF blockade resulted in tumor shrinkage with decreased MVD. Other preclinical studies similarly supported the clinical exploration of anti-angiogenesis agents in $\mathrm{PDAC}^{[41,53-55]}$.

Initial trials focused on concurrent combination therapy with an anti-angiogenic agent with cytotoxic chemotherapy. In a phase II trial published by Kindler et al. ${ }^{[5]}, 52$ patients with advanced PDAC were treated with upfront bevacizumab and gemcitabine. Median survival measured 8.8 months, with $21 \%$ of partial responses and $46 \%$ with stable disease ${ }^{[56]}$. Additional phase II trials investigated the combination of bevacizumab with other agents, including docetaxel, erlotinib, gemcitabine with cisplatin, and gemcitabine with capecitabine $e^{[57-60]}$.

In the phase III setting, the CALGB 80303 trial randomized patients with untreated metastatic PDAC to gemcitabine/bevacizumab vs. gemcitabine/placebo, with a similar median OS of 5.8 and 5.9 months between the two arms, respectively ${ }^{[6]]}$. Bevacizumab in combination with erlotinib, a tyrosine kinase inhibitor that targets HER1/EGFR, was the next anti-angiogenic combination to be reported in a phase III clinical trial, with a similar OS between the two arms. There was a statistically significant improvement in PFS, with a hazard ratio of 0.73 , but this has not changed practice ${ }^{[62]}$. Another EGFR inhibitor, cetuximab, was combined with bevacizumab with or without gemcitabine in a phase II trial ${ }^{[63]}$. This study was terminated early for futility, suggesting that dual VEGF and EGFR blockade was not an effective mechanism in PDAC. 
Aflibercept, a recombinant fusion protein that "traps" VEGF, was studied in combination with gemcitabine in a phase III trial that was also stopped early for lack of efficacy ${ }^{[64]}$. Other VEGF-inhibiting tyrosine kinase inhibitors have been studied in combination with chemotherapy. With potentially promising results in the early phase setting, the phase III trial with axitinib and gemcitabine did not meet its primary endpoint and the trial was stopped early ${ }^{[6-67]}$. Sorafenib represented a similar trajectory, with variable results in the early phase setting when combined with chemotherapy ${ }^{[6-71]}$. The phase III BAYPAN trial comparing sorafenib with gemcitabine $v$ s. placebo with gemcitabine also did not meet its primary endpoint of PFS, with no significant difference in median OS, either ${ }^{[72]}$. Additional tyrosine kinase inhibitors, including cabozantinib, sunitinib, vandetanib, and vatalanib, have been investigated in early phase trials with disappointing results $^{[73-77]}$.

In addition to drugs with a primary VEGF target, immunomodulatory drugs, including lenalidomide, thalidomide, and pomalidomide, which also act as VEGF inhibitors, have also been studied in PDAC. Thalidomide was combined with capecitabine in a phase II trial of 31 patients with advanced PDAC, with a median PFS measuring 2.7 months and OS of 6.1 months $^{[78]}$. Pomalidomide was studied in a phase I setting with gemcitabine, and found to be well-tolerated ${ }^{[79]}$. Lenalidomide, a more potent immunomodulatory drug, was shown to decrease ERK expression and enhance gemcitabine activity ${ }^{[80]}$. Lenalidomide was subsequently studied in a phase II trial in combination with gemcitabine ${ }^{[8]}$. Low response rates, and a limited 6-month OS of $37 \%$ have halted continued development in the setting of PDAC.

EndoTAG-1, cationic liposomes formulated with paclitaxel, is a novel antiangiogenic agent that is still being investigated ${ }^{[82]}$. A phase II study of EndoTAG-1 with gemcitabine in chemotherapy-naïve patients demonstrated good tolerability ${ }^{[83]}$. EndoTAG-1 is now being studied in a prospective phase III setting with gemcitabine in patients with advanced PDAC after FOLFIRINOX failure (NCT03126435), and we await readout of these results ${ }^{[84]}$.

Among the largely negative trials involving anti-angiogenesis agents, Reni et al. ${ }^{[85]}$ explored a different approach using maintenance single agent sunitinib among patients who demonstrated disease stability after 6 months of cytotoxic chemotherapy. In this phase II study, 22\% of patients remained progression-free at 6 months, with 2 -year overall survival of $23 \%$ and stable disease of $52 \%$. While sunitinib and other antiangiogenic agents were not effective alone or concurrently with systemic therapy as discussed earlier, this suggests that targeting the VEGFR pathway may be successful after optimal cytoreduction with traditional chemotherapy agents. Rethinking traditional paradigms of treatment in PDAC, such as sequencing an antiangiogenic strategy after chemotherapy in this case, may unveil novel opportunities for treatment.

\section{LEARNING FROM TRADITIONAL APPROACHES IN THE IMMUNOTHERAPY ERA}

Targeting and depleting HA represents another example of extensive bench to bedside work. An ECM dense with HA forms a physical barrier that precludes successful diffusion of small molecules from the surrounding vasculature to the tumor itself, thus inhibiting successful drug delivery of therapeutic agents ${ }^{[14,86]}$. Using GEM models of PDAC, Provenzano et al. ${ }^{[14]}$ demonstrated that degradation of hyaluronan with PEGPH20, a pegylated human recombinant $\mathrm{PH} 20$ hyaluronidase, leads to a significant decrease in IFP, thus removing this physical barrier. In vitro studies using gemcitabine with PEGPH20 demonstrated that PEGPH20 successfully altered the tumor microenvironment, with a subsequent reduction in tumor size. In a separate study, Jacobetz et al. ${ }^{[87]}$ also showed that the administration of PEGPH20 resulted in the reexpansion of vasculature and increased intratumoral concentrations of gemcitabine and doxorubicin. 
With this substantial preclinical evidence of efficacy in modifying the tumor microenvironment and enhancing drug delivery, early phase combination trials of PEGPH20 with FOLFIRINOX or gemcitabinebased chemotherapy were undertaken ${ }^{[88-90]}$. In the SWOG $\$ 1313$ phase Ib/II clinical trial, PEGPH20 was administered with modified (m)FOLFIRINOX among patients with unselected HA levels, and compared to mFOLFIRINOX alone ${ }^{[90]}$. In a preplanned interim safety analysis, there was a significant increase of thromboembolic events in the PEGPH20/mFOLFIRINOX arm, necessitating an amendment to incorporate enoxaparin prophylaxis. One year later, in a preplanned interim analysis, the hazard ratio for OS was significantly increased at 2.07, with a median OS of 7.7 months (PEGPH20/mFOLFIRINOX arm) vs. 14.4 months in the mFOLFIRINOX arm, resulting in early study closure. Potential explanations for these unexpected results include increased gastrointestinal toxicity and thromboembolic events in the combination arm, leading to dose delays and reduced drug exposure. The impact of FOLFIRINOX or granulocyte colony-stimulating growth factor on the tumor microenvironment is also unclear and may contribute to the difference in survival.

By contrast, the HALO-202 study compared the combination of PEGPH20 with gemcitabine and nabpaclitaxel to gemcitabine and nab-paclitaxel in a randomized phase II trial among patients with unselected HA status ${ }^{[89]}$. PFS was longer in the combination arm among all patients, and in the subgroup of patients with HA-high tumors. Given that this study achieved its primary endpoints, the prospective phase III HALO-301 trial was launched. Patients with HA-high PDAC were randomized to gemcitabine and nabpaclitaxel with or without PEGPH20, coupled with enoxaparin prophylaxis ${ }^{[91]}$. OS was similar between the two groups, measuring 11.2 months in the PEGPH20 arm compared to 11.5 months in the placebo/chemotherapy arm. PFS was also similar (median of 7.1 months in both arms), as was the objective response rate ( $47 \%$ vs. 36\% in the PEGPH20/chemotherapy and placebo/chemotherapy arms, respectively). Despite the compelling pathophysiological preclinical data and biologic rationale, these disappointing negative phase III clinical trial results highlight the inherent complexity of the tumor microenvironment and stromal remodeling.

Prior to the readout of the negative phase III trial with PEGPH20, combinations with immunotherapeutic agents were also being explored. In the MORPHEUS phase Ib/II trial (NCT03193190), patients with advanced PDAC received second-line PEGPH20 with atezolizumab ${ }^{[2]}$. Response rates measured $6 \%$ and median OS was 7.1 months, compared to 6.8 months in the control arm. While this combination did not benefit all trial participants, the response rate of $6 \%$ still warranted correlative analyses for potential predictive biomarkers to identify responders and to inform future immunotherapeutic combinations. Furthermore, depletion of HA may still prove effective as an adjunct to cellular based treatments, such as chimeric antigen receptor (CAR) T-cell therapy.

\section{CANCER-ASSOCIATED FIBROBLASTS AS THE NEXT FRONTIER?}

iCAFs contribute to inhibiting the immune response in PDAC, with increased NF- $\kappa B$ signaling ${ }^{[18]}$. This leads to increased CXCL12 expression, which blocks cytotoxic T cell infiltration. CXCR4 is also involved in this pathway, and preclinical data demonstrated that CXCR4-CXCL12 inhibition enhanced PD-L1 inhibitor sensitivity ${ }^{[93,94]}$. The recently published phase IIa COMBAT trial investigated motixafortide (BL-8040), a CXCR4 antagonist, in combination with pembrolizumab, 5-fluorouracil, and nanoliposomal irinotecan ${ }^{[95]}$. While median OS measured 3.3 months, the cohort with motixafortide, pembrolizumab, and chemotherapy demonstrated an ORR of $32 \%$ and median duration of response of 7.8 months. Given the limited efficacy of immune checkpoint blockade with or without chemotherapy in patients with biomarker-unselected PDAC, the addition of a CXCR4 inhibitor may improve the efficacy of immunotherapeutic strategies ${ }^{[06,97]}$. Another combination therapy with motixafortide, this time with cemiplimab, gemcitabine, and nab-paclitaxel, is 
currently being investigated (NCT04543071; Table 1) ${ }^{[98]}$. NOX4 has also been identified as another important factor in the immune regulation by CAFs, and preclinical studies demonstrated that NOX 4 inhibition with setanaxib helped to mediate immunotherapy resistance ${ }^{[99]}$. This pathway may be yet another avenue to overcome immunotherapeutic resistance.

IL-6, also secreted by iCAFs, is actively being studied in enhancing the efficacy of PD-L1 blockade in PDAC. Il-6 subsequently activates STAT3 signaling and plays a role in PDAC pathogenesis ${ }^{[1,27,100]}$. Nab-paclitaxel, part of the chemotherapy backbone in the approved armamentarium against advanced PDAC, has been shown to disrupt the stroma by decreasing IL-6 expression ${ }^{[101,102]}$. Furthermore, Il-6 inhibition, when administered in combination with PD-L1 blockade, improved survival outcomes in GEM models, and demonstrated increased T cell infiltration ${ }^{[103]}$. Siltuximab, a monoclonal antibody targeting IL- 6 , has been shown to be well-tolerated in an early phase clinical trial of patients with advanced solid tumors ${ }^{[104]}$. With the preclinical mechanistic rationale of combination IL-6 inhibition with immunotherapy, siltuximab is now being investigated with spartalizumab in a phase Ib/II trial (NCT04191421) ${ }^{[105]}$. Tocilizumab, another IL-6 inhibitor, is also being studied with gemcitabine and nab-paclitaxel chemotherapy in a phase II setting $(\mathrm{NCT} 02767557)^{[106]}$. Results from these trials are pending, and correlative studies may help to further elucidate the role of IL-6 inhibition in PDAC.

Another member of the IL- 6 cytokine family, leukemia inhibitory factor (LIF), is produced by PSCs and stimulated by KRAS mutations ${ }^{[107,108]}$. LIF serves as a critical paracrine factor in STAT3 activation in pancreatic cancer cells. Circulating LIF levels have been shown to correlate with responses to chemotherapy, suggesting its role as a potential biomarker ${ }^{[109]}$. In a preclinical $K R A S^{G 12 D}$ pancreatic mouse model, LIFneutralizing antibodies combined with gemcitabine appeared to be synergistic and successfully inhibited tumor growth ${ }^{[108]}$. This represents yet another potential therapeutic target to be further investigated.

Another important signaling pathway identified in iCAFs includes Janus Kinase (JAK)-STAT and IL-1 mediated signaling ${ }^{[110]}$. In murine models, ruxolitinib, an oral JAK1 and JAK2 inhibitor, decreased tumor cell proliferation ${ }^{[11]}$. Despite potentially favorable early phase results, ruxolitinib combined with capecitabine did not result in an OS benefit and phase III trials were stopped early for futility ${ }^{[12,113]}$. IL-1 receptor blockade using anakinra, in combination with FOLFIRINOX, was investigated in a phase I trial, with preliminary results presented in abstract form demonstrating safety and tolerability $(\mathrm{NCT} 02021422)^{[114]}$.

Platelet-derived growth factor (PDGFR)- $\alpha$ has been identified as a prominent cell surface marker, with Saa3 overexpression, particularly in $\mathrm{iCAF}^{[115]}$. While other tyrosine kinase inhibitors discussed previously were primarily studied for their anti-angiogenic properties, masitinib is a tyrosine kinase inhibitor targeting PDGFR $\alpha / \beta$, c-Kit, and Lyn with preclinical evidence demonstrating improved sensitivity to gemcitabine when administered together ${ }^{[116]}$. While early phase trial results appeared promising, median OS with masitinib and gemcitabine measured 7.7 months vs. 7.1 months compared to a placebo and gemcitabine arm in a phase III trial ${ }^{[17,118]}$. Olaratumab, a monoclonal antibody that binds to PDGFR $\alpha$, is also being investigated in a phase Ib/II trial with gemcitabine and nab-paclitaxel in patients with untreated metastatic $\mathrm{PDAC}(\mathrm{NCT} 03086369)^{[119]}$.

While many of these clinical trials stemmed from initial favorable findings in the lab, one of the key differences in these recent trials has been the incorporation of correlative studies and treatment-related biopsies to better comprehend in vivo effects. While we eagerly await the clinical trial results investigating these novel strategies, equally important will be the correlative findings that may provide further insights. 
Table 1. Selected clinical trials that are ongoing with PDAC tumor microenvironment targets

\begin{tabular}{|c|c|c|c|c|c|}
\hline $\begin{array}{l}\text { Experimental } \\
\text { agent }\end{array}$ & Trial ID & Experimental regimen & Trial design & Primary endpoint & $\begin{array}{l}\text { Estimated } \\
\text { completion } \\
\text { date }\end{array}$ \\
\hline $\begin{array}{l}\text { Motixafortide } \\
\text { (CXCR4 antagonist) }\end{array}$ & NCT04543071 ${ }^{[98]}$ & $\begin{array}{l}\text { Motixafortide, } \\
\text { cemiplimab, gemcitabine, } \\
\text { nab-paclitaxel }\end{array}$ & $\begin{array}{l}\text { Phase II non- } \\
\text { randomized }\end{array}$ & ORR & July 2025 \\
\hline $\begin{array}{l}\text { Olaptesed pegol } \\
\text { (CXCL12 antagonist) }\end{array}$ & NCT03168139 $9^{[164]}$ & $\begin{array}{l}\text { Olaptesed +/- } \\
\text { pembrolizumab }\end{array}$ & $\begin{array}{l}\text { Phase I/II non- } \\
\text { randomized }\end{array}$ & $\begin{array}{l}\text { Pharmacodynamics and } \\
\text { safety (adverse events) }\end{array}$ & $\begin{array}{l}\text { March } 2020 \text { (not } \\
\text { yet reported) }\end{array}$ \\
\hline $\begin{array}{l}\text { Tocilizumab (IL-6 } \\
\text { inhibitor) }\end{array}$ & NCT02767557 $7^{[106]}$ & $\begin{array}{l}\text { Tocilizumab, } \\
\text { gemcitabine, nab- } \\
\text { paclitaxel }\end{array}$ & $\begin{array}{l}\text { Phase II } \\
\text { randomized }\end{array}$ & OS at 6 months & January 2021 \\
\hline $\begin{array}{l}\text { Siltuximab (IL-6 } \\
\text { inhibitor) }\end{array}$ & NCT04191421 $1^{[105]}$ & Siltuximab, spartalizumab & $\begin{array}{l}\text { Phase lb/II } \\
\text { non- } \\
\text { randomized }\end{array}$ & Recommended phase II dose & December 2022 \\
\hline $\begin{array}{l}\text { L-DOS47 } \\
\text { (CEACAM6 } \\
\text { inhibitor) }\end{array}$ & NCT04203641 ${ }^{[165]}$ & L-DOS47, doxorubicin & $\begin{array}{l}\text { Phase lb/II } \\
\text { non- } \\
\text { randomized }\end{array}$ & ORR and adverse events & October 2021 \\
\hline $\begin{array}{l}\text { Defactinib (focal } \\
\text { adhesion kinase } \\
\text { inhibitor) }\end{array}$ & NCT02546531 $1^{[166-168]}$ & $\begin{array}{l}\text { Defactinib, } \\
\text { pembrolizumab, } \\
\text { gemcitabine }\end{array}$ & $\begin{array}{l}\text { Phase I non- } \\
\text { randomized }\end{array}$ & Maximum tolerated dose & $\begin{array}{l}\text { Expansion cohort } \\
\text { ongoing }\end{array}$ \\
\hline $\begin{array}{l}\text { Olaratumab (PDGFR } \alpha \\
\text { inhibitor) }\end{array}$ & NCT03086369 $9^{[119]}$ & $\begin{array}{l}\text { Olaratumab, gemcitabine, } \\
\text { nab-paclitaxel }\end{array}$ & $\begin{array}{l}\text { Phase lb/II } \\
\text { non- } \\
\text { randomized }\end{array}$ & $\begin{array}{l}\text { Number of patients with DLTs } \\
\text { (phase Ib), OS (phase II) }\end{array}$ & January 2022 \\
\hline $\begin{array}{l}\text { Canakinumab (IL-1 } \beta \\
\text { inhibitor) }\end{array}$ & NCT04581343 $3^{[169]}$ & $\begin{array}{l}\text { Canakinumab, } \\
\text { spartalizumab, } \\
\text { gemcitabine, nab- } \\
\text { paclitaxel }\end{array}$ & $\begin{array}{l}\text { Phase lb non- } \\
\text { randomized }\end{array}$ & Recommend phase II/III dose & March 2021 \\
\hline $\begin{array}{l}\text { Paracalcitol (vitamin } \\
\text { D analogue) }\end{array}$ & NCT03331562 $2^{[160,161]}$ & $\begin{array}{l}\text { Paracalcitol, } \\
\text { pembrolizumab }\end{array}$ & $\begin{array}{l}\text { Phase II } \\
\text { randomized }\end{array}$ & $\begin{array}{l}\text { Percentage of patients with } \\
\text { radiographic progression at } 6 \\
\text { months }\end{array}$ & $\begin{array}{l}\text { July } 2020 \text { (results } \\
\text { not yet reported) }\end{array}$ \\
\hline
\end{tabular}

PDAC: Pancreatic ductal adenocarcinoma; OS: overall survival.

\section{WHAT ABOUT MYELOID SUPPRESSION IN THE TUMOR MICROENVIRONMENT?}

Mesenchymal stem cell CAFs have also been identified, with increased expression of granulocytemacrophage colony-stimulating factor (GM-CSF) leading to downstream epithelial-mesenchymal transition and subsequent oncogenesis ${ }^{[120]}$. Inhibition of GM-CSF, particularly via CSF-1 receptor (CSF-1R) blockade, depletes the accumulation of tumor-associated macrophages (TAMs ${ }^{[2,21]}$. TAMs have been demonstrated to block $\mathrm{T}$ cell intratumoral infiltration and can limit PD-1 blockade, thus contributing to immune checkpoint inhibitor resistance ${ }^{[121-123]}$. Cabiralizumab, a monoclonal antibody targeting CSF-1R, has been studied in combination with nivolumab ${ }^{[124,125]}$. In a phase II study, cabiralizumab is being investigated with nivolumab and various chemotherapy combinations (gemcitabine/nab-paclitaxel, 5-FU/oxaliplatin/leucovorin, or investigator's choice). The preliminary safety cohort has been completed, but efficacy results are being awaited (NCT03336216) ${ }^{[126,127]}$. Another anti-CSF1R monoclonal antibody, AMG 820, was recently reported with pembrolizumab in an early phase study among patients with various tumor types, including 31 patients with PDAC ${ }^{[128]}$. There were no partial responses, and median time to progression measured 2.1 months. This did not meet the predefined threshold for efficacy, so this combination is not being further investigated.

In addition to TAMs, inflammatory monocytes facilitate PDAC development and immunosuppression within the tumor microenvironment, with the CCR2 axis playing a pivotal $\operatorname{role}^{[129,130]}$. An oral CCR2 antagonist (PF-04136309) was administered in combination with gemcitabine and nab-paclitaxel in patients with previously untreated metastatic PDAC in a phase $\mathrm{Ib}$ trial ${ }^{[131]}$. While there was an ORR of $23.8 \%$, there was also a incidence rate of $24 \%$ for pulmonary toxicity, thus raising a significant safety concern. In another 
early phase trial, Linehan et al. ${ }^{[132]}$ reported using a different CCR antagonist, CCX872, this time in combination with FOLFIRINOX. Overall survival at 18 months measured 29\%, with correlative studies demonstrating reduction of circulating and inflammatory monocytes, and myeloid-derived suppressor cells. In the borderline resectable/locally advanced setting, the combination of the oral CCR2 inhibitor with FOLFIRINOX in a phase Ib trial showed a $49 \%$ rate of response with no increased pulmonary toxicity ${ }^{[133]}$. While CCR2 antagonists have been combined with chemotherapy in an attempt to overcome chemoresistance, there is also preclinical rationale for exploring the combination with immune checkpoint inhibitors ${ }^{[134]}$. Further investigation of these combination approaches is merited.

\section{OTHER STROMAL TARGETS}

Connective tissue growth factor (CTGF) is implicated in promoting fibrosis in PDAC cells ${ }^{[135]}$. Pamrevlumab, a monoclonal antibody targeting CTGF, in combination with gemcitabine and nab-paclitaxel as neoadjuvant therapy demonstrated a remarkable decrease of $20.6 \%$ in size of target lesions in a phase I/II trial ${ }^{[136]}$. Based on these exciting results, the phase III trial using this combination is now being explored $(\mathrm{NCT} 03941093)^{[137]}$. Further exploration in the advanced setting may also be warranted given these promising findings.

Matrix metalloproteinases (MMPs) have also been explored as a therapeutic target within the PDAC tumor microenvironment. MMPs are proteolytic enzymes that facilitate ECM degradation, with increased MMPs leading to ECM degradation and allowing for increased tumor invasion and metastasis ${ }^{[138]}$. BAY 12-9566, an oral MMP inhibitor, was compared to gemcitabine in a phase III trial, but this was terminated after an interim analysis identified shorter median OS in the BAY 12-9566 arm compared to the control arm $^{[139]}$. Marimastat, another oral MMP inhibitor, demonstrated encouraging results in the phase II setting ${ }^{[140]}$. When marimastat was combined with gemcitabine in a randomized phase III trial, there was no significant difference in OS when compared to gemcitabine alone ${ }^{[141]}$. A recent phase I trial of andecaliximab, a monoclonal antibody that inhibits MMP-9, in combination with gemcitabine and nab-paclitaxel in patients with advanced PDAC demonstrated tolerability and an overall response rate of $44.4 \%^{[142]}$. However, further development of andecaliximab was stopped after a phase III study among patients with gastric and gastroesophageal junction cancer was negative ${ }^{[143]}$.

Heparin sulfate proteoglycans supply growth factors and cytokines to the tumor microenvironment ${ }^{[144]}$. Administration of low molecular weight heparin has demonstrated anti-angiogenic, antiproliferative, and immune modulatory effects, but the bleeding risk is significant and must be considered prior to clinical $u \mathrm{e}^{[145,146]}$. A rationally engineered heparin sulfate with decreased anticoagulant effects, necuparanib, has been designed with early phase results supporting further investigation ${ }^{[147]}$. O'Reilly et al. ${ }^{[148]}$ reported the results of the phase II trial of gemcitabine/nab-paclitaxel with or without necuparanib. Median OS measured 10.71 months in the necuparanib arm, compared to 9.99 months in the placebo arm, and the study was terminated early for futility.

Preclinical studies showed that the Bruton tyrosine kinase (BTK) and PI3K $\gamma$ interact to promote M2 polarization, resulting in increased suppression of the immune system within the tumor microenvironment and promoted PDAC growth ${ }^{[149]}$. The administration of ibrutinib, an oral BTK inhibitor, demonstrated efficacy in mouse models, leading to the phase III RESOLVE trial evaluating ibrutinib in combination with gemcitabine and nab-paclitaxel in patients with untreated advanced PDAC ${ }^{[150,151]}$. There was no difference in OS or PFS with the addition of ibrutinib. 
While targeting of the renin-angiotensin-aldosterone system (RAAS) has traditionally been used in the treatment of hypertension and cardiac disorders, angiotensin II has also been reported to stimulate stromal cells, including fibroblasts, with subsequent cancer cell proliferation ${ }^{[152]}$. Losartan and lisinopril, inhibitors of the RAAS pathway, have been shown to decrease collagen and hyaluronan in preclinical models ${ }^{[153,154]}$. In a phase II trial of 49 patients with locally advanced PDAC treated with neoadjuvant FOLFIRINOX, losartan and chemoradiation, there was an impressive Ro resection rate of $61 \%^{[155]}$. In a retrospective study where RNA-Seq was used for resected pancreatic primaries, chronic use of RAAS inhibitors was associated with longer survival in patients without metastatic disease ${ }^{[156]}$. Taken together, further study of adjunct RAAS inhibition as a stromal target is warranted in larger prospective studies and should also be explored in the metastatic setting.

Other avenues being explored with significant interest include high-dose vitamin D and all-trans retinoic acid (ATRA). Preclinical studies demonstrated that the vitamin D receptor expression occurs in PDAC stroma. Administration of calcipotriol, a vitamin D receptor ligand, subsequently decreased inflammatory cytokines and growth factors ${ }^{[157]}$. Calcipotriol has also been shown to decrease $\mathrm{T}$ cell effector function, thus providing justification that combination vitamin $\mathrm{D}$ analogue with immune checkpoint blockade may be synergistic. Results from a pilot study of 24 patients receiving paracalcitol, nivolumab, nab-paclitaxel, gemcitabine, and cisplatin demonstrated an ORR of $83 \%$, with a median PFS of 8.17 months and median OS of 15.3 months. This study is now being expanded further (NCT02754726) ${ }^{[158,159]}$. Another phase II trial is investigating the role of a vitamin D analogue with a PD-1 inhibitor as maintenance treatment for patients who have achieved maximal response with chemotherapy (NCT03331562) $)^{[160,161]}$. ATRA, a vitamin A derivative, was administered with gemcitabine in GEM models, with decreased tumor size ${ }^{[162]}$. An early phase trial consisting of 28 patients who received ATRA, gemcitabine, and nab-paclitaxel demonstrated tolerability. Preliminary median OS measured 11.7 months, and this regimen will be further investigated in a planned phase IIb trial (NCT04241276) ${ }^{[163]}$. Selected ongoing clinical trials focused on tumor microenvironment targets are highlighted in Table 1.

\section{CONCLUSIONS AND FUTURE DIRECTIONS}

Over the last several decades, many lessons have been learned both in trial design and understanding of the tumor microenvironment. The majority of clinical trials now include an interim analysis for futility to allow for an early signal to be detected and to avoid unnecessary exposure and toxicity to a futile treatment. In addition, the incorporation of treatment-related biopsies can provide key correlative insights and contribute to biomarker identification to inform future studies. With the advent of novel technologies and advanced sequencing techniques, there is growing understanding of the make-up and complex interplay between stromal factors. Furthermore, an increased recognition of the role of the tumor environment in both chemo and immunotherapeutic resistance will help to improve drug design and delivery. Taken together, we are optimistic that these ongoing collaborative efforts will improve the quality of life and oncologic care for patients with PDAC.

\section{DECLARATIONS}

\section{Authors' contributions}

Contributed to the writing and editing of this manuscript: Tsang ES, Tempero MA

\section{Availability of data and materials}

Not applicable. 


\section{Financial support and sponsorship}

None.

\section{Conflicts of interest}

Both authors declared that there are no conflicts of interest.

\section{Ethical approval and consent to participate}

Not applicable.

\section{Consent for publication}

Not applicable.

\section{Copyright}

(c) The Author(s) 2021.

\section{REFERENCES}

1. . American Cancer Society. Cancer Facts \& Figures 2019.

2. Tempero MA, Malafa MP, Al-Hawary M, et al. Pancreatic adenocarcinoma, version 2.2017, NCCN Clinical Practice Guidelines in oncology. J Natl Compr Canc Netw 2017;15:1028-61. DOI PubMed

3. Golan T, Hammel P, Reni M, et al. Maintenance olaparib for germline BRCA-mutated metastatic pancreatic cancer. $N$ Engl $J$ Med 2019;381:317-27. DOI PubMed PMC

4. Bailey P, Chang DK, Nones K, et al. Genomic analyses identify molecular subtypes of pancreatic cancer. Nature 2016;531:47-52. DOI PubMed

5. Collisson EA, Bailey P, Chang DK, et al. Molecular subtypes of pancreatic cancer. Nat Rev Gastroenterol Hepatol 2019;16:207-20. DOI PubMed

6. Moffitt RA, Marayati R, Flate EL, et al. Virtual microdissection identifies distinct tumor-and stroma-specific subtypes of pancreatic ductal adenocarcinoma. Nat Genet 2015;47:1168-78. DOI PubMed PMC

7. Karasinska JM, Topham JT, Kalloger SE, et al. Altered gene expression along the glycolysis-cholesterol synthesis axis is associated with outcome in pancreatic cancer. Clin Cancer Res 2019;26:135-46. DOI PubMed

8. O'Kane GM, Grunwald BT, Jang GH, et al. GATA6 expression distinguishes classical and basal-like subtypes in advanced pancreatic cancer. Clin Cancer Res 2020;26:4901-10. DOI PubMed

9. Knudsen ES, Vail P, Balaji U, et al. Stratification of pancreatic ductal adenocarcinoma: combinatorial genetic, stromal, and immunologic markers. Clin Cancer Res 2017;23:4429-40. DOI PubMed PMC

10. Hosein AN, Brekken RA, Maitra A. Pancreatic cancer stroma: an update on therapeutic targeting strategies. Nat Rev Gastroenterol Hepatol 2020;17:487-505. DOI PubMed

11. Schnittert J, Bansal R, Prakash J. Targeting pancreatic stellate cells in cancer. Trends Cance ;5:128-42. DOI PubMed

12. Binkley CE, Zhang L, Greenson JK, et al. The molecular basis of pancreatic fibrosis: common stromal gene expression in chronic pancreatitis and pancreatic adenocarcinoma. Pancreas 2004;29:254-63. DOI PubMed

13. Bachem MG, Schunemann M, Ramadani M, et al. Pancreatic carcinoma cells induce fibrosis by stimulating proliferation and matrix synthesis of stellate cells. Gastroenterology 2005;128:907-21. DOI PubMed

14. Provenzano PP, Cuevas C, Chang AE, et al. Enzymatic targeting of the stroma ablates physical barriers to treatment of pancreatic ductal adenocarcinoma. Cancer Cell 2012;21:418-29. DOI PubMed PMC

15. Heldin CH, Rubin K, Pietras K, et al. High interstitial fluid pressure - an obstacle in cancer therapy. Nat Rev Cancer 2004;4:806-13. DOI PubMed

16. Butcher DT, Alliston T, Weaver VM. A tense situation: forcing tumour progression. Nat Rev Cancer 2009;9:108-22. DOI PubMed PMC

17. Harris AL. Hypoxia--a key regulatory factor in tumour growth. Nat Rev Cancer 2002;2:38-47. DOI PubMed

18. Garg B, Giri B, Modi S, et al. NFkappaB in pancreatic stellate cells reduces infiltration of tumors by cytotoxic T cells and killing of cancer cells, via up-regulation of CXCL12. Gastroenterology 2018;155:880-91. DOI PubMed PMC

19. Nagathihalli NS, Castellanos JA, VanSaun MN, et al. Pancreatic stellate cell secreted IL-6 stimulates STAT3 dependent invasiveness of pancreatic intraepithelial neoplasia and cancer cells. Oncotarget 2016;7:65982-92. DOI PubMed PMC

20. Lin EY, Nguyen AV, Russell RG, et al. Colony-stimulating factor 1 promotes progression of mammary tumors to malignancy. $J$ Exp Med 2001;193:727-40. DOI PubMed PMC

21. Pollard JW. Tumour-educated macrophages promote tumour progression and metastasis. Nat Rev Cancer 2004;4:71-8. DOI PubMed

22. Elyada E, Bolisetty M, Laise P, et al. Cross-species single-cell analysis of pancreatic ductal adenocarcinoma reveals antigenpresenting cancer-associated fibroblasts. Cancer Discov 2019;9:1102-23. DOI PubMed PMC 
23. Collins MA, Bednar F, Zhang Y, et al. Oncogenic Kras is required for both the initiation and maintenance of pancreatic cancer in mice. J Clin Invest 2012;122:639-53. DOI PubMed PMC

24. Zhong Y, Macgregor-Das A, Saunders T, et al. Mutant p53 together with TGFbeta signaling influence organ-specific hematogenous colonization patterns of pancreatic cancer. Clin Cancer Res 2017;23:1607-20. DOI PubMed PMC

25. Collisson EA, Sadanandam A, Olson P, et al. Subtypes of pancreatic ductal adenocarcinoma and their differing responses to therapy. Nat Med 2011;17:500-3. DOI PubMed PMC

26. Liu Y, Cao X. Characteristics and significance of the pre-metastatic niche. Cancer Cell 2016;30:668-81. DOI PubMed

27. Lee JW, Stone ML, Porrett PM, et al. Hepatocytes direct the formation of a pro-metastatic niche in the liver. Nature 2019;567:24952. DOI PubMed PMC

28. Costa-Silva B, Aiello NM, Ocean AJ, et al. Pancreatic cancer exosomes initiate pre-metastatic niche formation in the liver. Nat Cell Biol 2015;17:816-26. DOI PubMed PMC

29. Grunwald B, Harant V, Schaten S, et al. Pancreatic premalignant lesions secrete tissue inhibitor of metalloproteinases-1, which activates hepatic stellate cells via CD63 signaling to create a premetastatic niche in the liver. Gastroenterology 2016;151:1011-24. DOI PubMed

30. Lee JC, Mehdizadeh S, Smith J, et al. Regulatory T cell control of systemic immunity and immunotherapy response in liver metastasis. Sci Immunol 2020;5:eaba0759. DOI PubMed PMC

31. Marechal R, Bachet JB, Calomme A, et al. Sonic hedgehog and gli1 expression predict outcome in resected pancreatic adenocarcinoma. Clin Cancer Res 2015;21:1215-24. DOI PubMed

32. Feldmann G, Dhara S, Fendrich V, et al. Blockade of hedgehog signaling inhibits pancreatic cancer invasion and metastases: a new paradigm for combination therapy in solid cancers. Cancer Res 2007;67:2187-96. DOI PubMed PMC

33. Thayer SP, di Magliano MP, Heiser PW, et al. Hedgehog is an early and late mediator of pancreatic cancer tumorigenesis. Nature 2003;425:851-6. DOI PubMed PMC

34. Lee JJ, Perera RM, Wang H, et al. Stromal response to Hedgehog signaling restrains pancreatic cancer progression. Proc Natl Acad Sci USA 2014;111:E3091-100. DOI PubMed PMC

35. Jones S, Zhang X, Parsons DW, et al. Core signaling pathways in human pancreatic cancers revealed by global genomic analyses. Science 2008;321:1801-6. DOI PubMed PMC

36. Bailey JM, Mohr AM, Hollingsworth MA. Sonic hedgehog paracrine signaling regulates metastasis and lymphangiogenesis in pancreatic cancer. Oncogene 2009;28:3513-25. DOI PubMed PMC

37. Tian H, Callahan CA, DuPree KJ, et al. Hedgehog signaling is restricted to the stromal compartment during pancreatic carcinogenesis. Proc Natl Acad Sci USA 2009;106:4254-9. DOI PubMed PMC

38. Hwang RF, Moore TT, Hattersley MM, et al. Inhibition of the hedgehog pathway targets the tumor-associated stroma in pancreatic cancer. Mol Cancer Res 2012;10:1147-57. DOI PubMed PMC

39. Olive KP, Jacobetz MA, Davidson CJ, et al. Inhibition of hedgehog signaling enhances delivery of chemotherapy in a mouse model of pancreatic cancer. Science 2009;324:1457-61. DOI PubMed PMC

40. Richards DA, Stephenson J, Wolpin BM, et al. A phase Ib trial of IPI-926, a hedgehog pathway inhibitor, plus gemcitabine in patients with metastatic pancreatic cancer. JCO 2012;30:213. DOI

41. Stephenson J, Richards DA, Wolpin BM, et al. The safety of IPI-926, a novel hedgehog pathway inhibitor, in combination with gemcitabine in patients (pts) with metastatic pancreatic cancer. JCO 2011;29:4114. DOI

42. Ko AH, LoConte N, Tempero MA, et al. A phase I study of FOLFIRINOX Plus IPI-926, a hedgehog pathway inhibitor, for advanced pancreatic adenocarcinoma. Pancreas 2016;45:370-5. DOI PubMed PMC

43. Kim EJ, Sahai V, Abel EV, et al. Pilot clinical trial of hedgehog pathway inhibitor GDC-0449 (vismodegib) in combination with gemcitabine in patients with metastatic pancreatic adenocarcinoma. Clin Cancer Res 2014;20:5937-45. DOI PubMed PMC

44. Catenacci DV, Junttila MR, Karrison T, et al. Randomized phase Ib/II study of gemcitabine plus placebo or Vvismodegib, a hedgehog pathway inhibitor, in patients with metastatic pancreatic cancer. J Clin Oncol 2015;33:4284-92. DOI PubMed PMC

45. De Jesus-Acosta A, O'Dwyer PJ, Ramanathan RK, et al. A phase II study of vismodegib, a hedgehog (Hh) pathway inhibitor, combined with gemcitabine and nab-paclitaxel (nab-P) in patients (pts) with untreated metastatic pancreatic ductal adenocarcinoma (PDA). JCO 2014;32:257. DOI

46. Macarulla T, Tabernero J, Palmer DH, et al. A phase Ib dose escalation, safety, and tolerability study of sonidegib in combination with gemcitabine in patients with locally advanced or metastatic pancreatic adenocarcinoma. JCO 2016;34:371. DOI PubMed PMC

47. Lee K, Molenaar RJ, Klaassen R, et al. A Phase I study of LDE225 in combination with gemcitabine and nab-paclitaxel in patients with metastasized pancreatic cancer. Ann Oncol 2017;28:v260. DOI

48. Rhim AD, Oberstein PE, Thomas DH, et al. Stromal elements act to restrain, rather than support, pancreatic ductal adenocarcinoma. Cancer Cell 2014;25:735-47. DOI PubMed PMC

49. Ozdemir BC, Pentcheva-Hoang T, Carstens JL, et al. Depletion of carcinoma-associated fibroblasts and fibrosis induces immunosuppression and accelerates pancreas cancer with reduced survival. Cancer Cell 2014;25:719-34. DOI PubMed PMC

50. Seo Y, Baba H, Fukuda T, et al. High expression of vascular endothelial growth factor is associated with liver metastasis and a poor prognosis for patients with ductal pancreatic adenocarcinoma. Cancer 2000;88:2239-45. DOI PubMed

51. Niedergethmann M, Hildenbrand R, Wostbrock B, et al. High expression of vascular endothelial growth factor predicts early recurrence and poor prognosis after curative resection for ductal adenocarcinoma of the pancreas. Pancreas 2002;25:122-9. DOI PubMed

52. Baker CH, Solorzano CC, Fidler IJ. Blockade of vascular endothelial growth factor receptor and epidermal growth factor receptor 
signaling for therapy of metastatic human pancreatic cancer. Cancer Res 2002;62:1996-2003. PubMed

53. Itakura J, Ishiwata T, Friess H, et al. Enhanced expression of vascular endothelial growth factor in human pancreatic cancer correlates with local disease progression. Clin Cancer Res 1997;3:1309-16. PubMed

54. Luo J, Guo P, Matsuda K, et al. Pancreatic cancer cell-derived vascular endothelial growth factor is biologically active in vitro and enhances tumorigenicity in vivo. Int J Cancer 2001;92:361-9. DOI PubMed

55. Fukasawa M, Korc M. Vascular endothelial growth factor-trap suppresses tumorigenicity of multiple pancreatic cancer cell lines. Clin Cancer Res 2004;10:3327-32. DOI PubMed

56. Kindler HL, Friberg G, Singh DA, et al. Phase II trial of bevacizumab plus gemcitabine in patients with advanced pancreatic cancer. $J$ Clin Oncol 2005;23:8033-40. DOI PubMed

57. Astsaturov IA, Meropol NJ, Alpaugh RK, et al. Phase II and coagulation cascade biomarker study of bevacizumab with or without docetaxel in patients with previously treated metastatic pancreatic adenocarcinoma. Am J Clin Oncol 2011;34:70-5. DOI PubMed PMC

58. Javle M, Yu J, Garrett C, et al. Bevacizumab combined with gemcitabine and capecitabine for advanced pancreatic cancer: a phase II study. Br J Cancer 2009;100:1842-5. DOI PubMed PMC

59. Ko AH, Dito E, Schillinger B, et al. A phase II study evaluating bevacizumab in combination with fixed-dose rate gemcitabine and low-dose cisplatin for metastatic pancreatic cancer: is an anti-VEGF strategy still applicable? Invest New Drugs 2008;26:463-71. DOI PubMed

60. Ko AH, Venook AP, Bergsland EK, et al. A phase II study of bevacizumab plus erlotinib for gemcitabine-refractory metastatic pancreatic cancer. Cancer Chemother Pharmacol 2010;66:1051-7. DOI PubMed

61. Kindler HL, Niedzwiecki D, Hollis D, et al. Gemcitabine plus bevacizumab compared with gemcitabine plus placebo in patients with advanced pancreatic cancer: phase III trial of the Cancer and Leukemia Group B (CALGB 80303). J Clin Oncol 2010;28:3617-22. DOI PubMed PMC

62. Van Cutsem E, Vervenne WL, Bennouna J, et al. Phase III trial of bevacizumab in combination with gemcitabine and erlotinib in patients with metastatic pancreatic cancer. J Clin Oncol 2009;27:2231-7. DOI PubMed

63. Ko AH, Youssoufian H, Gurtler J, et al. A phase II randomized study of cetuximab and bevacizumab alone or in combination with gemcitabine as first-line therapy for metastatic pancreatic adenocarcinoma. Invest New Drugs 2012;30:1597-1606. DOI PubMed

64. Rougier P, Riess H, Manges R, et al. Randomised, placebo-controlled, double-blind, parallel-group phase III study evaluating aflibercept in patients receiving first-line treatment with gemcitabine for metastatic pancreatic cancer. Eur J Cancer 2013;49:2633-42. DOI PubMed

65. Spano JP, Chodkiewicz C, Maurel J, et al. Efficacy of gemcitabine plus axitinib compared with gemcitabine alone in patients with advanced pancreatic cancer: an open-label randomised phase II study. Lancet 2008;371:2101-8. DOI PubMed

66. Spano JP, Moore MJ, Pithavala YK, et al. Phase I study of axitinib (AG-013736) in combination with gemcitabine in patients with advanced pancreatic cancer. Invest New Drugs 2012;30:1531-9. DOI PubMed

67. Kindler HL, Ioka T, Richel DJ, et al. Axitinib plus gemcitabine versus placebo plus gemcitabine in patients with advanced pancreatic adenocarcinoma: a double-blind randomised phase 3 study. Lancet Oncol 2011;12:256-62. DOI PubMed

68. Cascinu S, Berardi R, Sobrero A, et al. Sorafenib does not improve efficacy of chemotherapy in advanced pancreatic cancer: A GISCAD randomized phase II study. Dig Liver Dis 2014;46:182-6. DOI PubMed PMC

69. El-Khoueiry AB, Ramanathan RK, Yang DY, et al. A randomized phase II of gemcitabine and sorafenib versus sorafenib alone in patients with metastatic pancreatic cancer. Invest New Drugs 2012;30:1175-83. DOI PubMed PMC

70. Kindler HL, Wroblewski K, Wallace JA, et al. Gemcitabine plus sorafenib in patients with advanced pancreatic cancer: a phase II trial of the University of Chicago Phase II Consortium. Invest New Drugs 2012;30:382-6. DOI PubMed PMC

71. Siu LL, Awada A, Takimoto CH, et al. Phase I trial of sorafenib and gemcitabine in advanced solid tumors with an expanded cohort in advanced pancreatic cancer. Clin Cancer Res 2006;12:144-51. DOI PubMed

72. Goncalves A, Gilabert M, Francois E, et al. BAYPAN study: a double-blind phase III randomized trial comparing gemcitabine plus sorafenib and gemcitabine plus placebo in patients with advanced pancreatic cancer. Ann Oncol 2012;23:2799-805. DOI PubMed

73. Zhen DB, Griffith KA, Ruch JM, et al. A phase I trial of cabozantinib and gemcitabine in advanced pancreatic cancer. Invest New Drugs 2016;34:733-9. DOI PubMed PMC

74. O'Reilly EM, Niedzwiecki D, Hall M, et al. A Cancer and Leukemia Group B phase II study of sunitinib malate in patients with previously treated metastatic pancreatic adenocarcinoma (CALGB 80603). Oncologist 2010;15:1310-9. DOI PubMed PMC

75. Middleton G, Palmer DH, Greenhalf W, et al. Vandetanib plus gemcitabine versus placebo plus gemcitabine in locally advanced or metastatic pancreatic carcinoma (ViP): a prospective, randomised, double-blind, multicentre phase 2 trial. Lancet Oncol 2017;18:48699. DOI PubMed

76. Dragovich T, Laheru D, Dayyani F, et al. Phase II trial of vatalanib in patients with advanced or metastatic pancreatic adenocarcinoma after first-line gemcitabine therapy (PCRT O4-001). Cancer Chemother Pharmacol 2014;74:379-87. DOI PubMed PMC

77. Kessler ER, Eckhardt SG, Pitts TM, et al. Phase I trial of vandetanib in combination with gemcitabine and capecitabine in patients with advanced solid tumors with an expanded cohort in pancreatic and biliary cancers. Invest New Drugs 2016;34:176-83. DOI PubMed PMC

78. Shi SB, Wang M, Niu ZX, et al. Phase II trial of capecitabine combined with thalidomide in second-line treatment of advanced pancreatic cancer. Pancreatology 2012;12:475-9. DOI PubMed

79. Infante JR, Jones SF, Bendell JC, et al. A phase I, dose-escalation study of pomalidomide (CC-4047) in combination with 
gemcitabine in metastatic pancreas cancer. Eur J Cancer 2011;47:199-205. DOI PubMed

80. Fryer RA, Barlett B, Galustian C, Dalgleish AG. Mechanisms underlying gemcitabine resistance in pancreatic cancer and sensitisation by the iMiD lenalidomide. Anticancer Res 2011;31:3747-56. PubMed

81. Infante JR, Arkenau HT, Bendell JC, et al. Lenalidomide in combination with gemcitabine as first-line treatment for patients with metastatic carcinoma of the pancreas: a Sarah Cannon Research Institute phase II trial. Cancer Biol Ther 2013;14:340-6. DOI PubMed PMC

82. Eichhorn ME, Ischenko I, Luedemann S, et al. Vascular targeting by EndoTAG-1 enhances therapeutic efficacy of conventional chemotherapy in lung and pancreatic cancer. Int J Cancer 2010;126:1235-45. DOI PubMed

83. Lohr JM, Haas SL, Bechstein WO, et al. Cationic liposomal paclitaxel plus gemcitabine or gemcitabine alone in patients with advanced pancreatic cancer: a randomized controlled phase II trial. Ann Oncol 2012;23:1214-22. DOI PubMed

84. Chen L, Su M. EndoTAG-1 plus gemcitabine versus gemcitabine alone in patients with measurable locally advanced and/or metastatic adenocarcinoma of the pancreas failed on FOLFIRINOX treatment (NCT03126435). JCO 2020;38:TPS4669. DOI

85. Reni M, Cereda S, Milella M, et al. Maintenance sunitinib or observation in metastatic pancreatic adenocarcinoma: a phase II randomised trial. Eur J Cancer 2013;49:3609-15. DOI PubMed

86. Wong KM, Horton KJ, Coveler AL, et al. Targeting the tumor stroma: the biology and clinical development of pegylated recombinant human hyaluronidase (PEGPH20). Curr Oncol Rep 2017;19:47. DOI PubMed

87. Jacobetz MA, Chan DS, Neesse A, et al. Hyaluronan impairs vascular function and drug delivery in a mouse model of pancreatic cancer. Gut 2013;62:112-20. DOI PubMed PMC

88. Hingorani SR, Harris WP, Beck JT, et al. Phase Ib study of PEGylated recombinant human hyaluronidase and gemcitabine in patients with advanced pancreatic cancer. Clin Cancer Res 2016;22:2848-54. DOI PubMed PMC

89. Hingorani SR, Zheng L, Bullock AJ, et al. HALO 202: Randomized phase II study of PEGPH20 plus nab-paclitaxel/gemcitabine versus nab-paclitaxel/gemcitabine in patients with untreated, metastatic pancreatic ductal adenocarcinoma. J Clin Oncol 2018;36:35966. DOI PubMed

90. Ramanathan RK, McDonough SL, Philip PA, et al. Phase IB/II randomized study of FOLFIRINOX plus pegylated recombinant human hyaluronidase versus FOLFIRINOX alone in patients with metastatic pancreatic adenocarcinoma: SWOG S1313. J Clin Oncol 2019;37:1062-9. DOI PubMed PMC

91. Van Cutsem E, Tempero MA, Sigal D, et al. Randomized phase III trial of pegvorhyaluronidase alfa with nab-paclitaxel plus gemcitabine for patients with hyaluronan-high metastatic pancreatic adenocarcinoma. J Clin Oncol 2020;38:3185-94. DOI PubMed $\mathrm{PMC}$

92. Ko AH, Lee J, ALSINA M, et al. Phase Ib/II open-label, randomized evaluation of 2L atezolizumab (atezo) + PEGPH20 versus control in MORPHEUS-pancreatic ductal adenocarcinoma (M-PDAC) and MORPHEUS-gastric cancer (M-GC). JCO 2020;38:4540. DOI

93. Feig C, Jones JO, Kraman M, et al. Targeting CXCL12 from FAP-expressing carcinoma-associated fibroblasts synergizes with antiPD-L1 immunotherapy in pancreatic cancer. Proc Natl Acad Sci USA 2013;110:20212-17. DOI PubMed PMC

94. Seo YD, Jiang X, Sullivan KM, et al. Mobilization of CD8(+) T cells via CXCR4 blockade facilitates PD-1 checkpoint therapy in human pancreatic cancer. Clin Cancer Res 2019;25:3934-45. DOI PubMed PMC

95. Bockorny B, Semenisty V, Macarulla T, et al. BL-8040, a CXCR4 antagonist, in combination with pembrolizumab and chemotherapy for pancreatic cancer: the COMBAT trial. Nat Med 2020;26:878-85. DOI PubMed

96. O'Reilly EM, Oh DY, Dhani N, et al. Durvalumab with or without tremelimumab for patients with metastatic pancreatic ductal adenocarcinoma: a phase 2 randomized clinical trial. JAMA Oncol 2019;5:1431-8. DOI PubMed PMC

97. Renouf DJ, Knox JJ, Kavan P, et al. LBA65 The Canadian Cancer Trials Group PA.7 trial: results of a randomized phase II study of gemcitabine (GEM) and nab-paclitaxel (Nab-P) vs GEM, nab-P, durvalumab (D) and tremelimumab (T) as first line therapy in metastatic pancreatic ductal adenocarcinoma (mPDAC). Ann Oncol 2020;31:S1195. DOI

98. US National Library of Medicine. Chemo4METPANC combination chemokine inhibitor, immunotherapy, and chemotherapy in patients with pancreatic adenocarcinoma. Available from: https://clinicaltrials.gov/ct2/show/NCT04543071. [Last accessed on 8 Jun 2021].

99. Ford K, Hanley CJ, Mellone M, et al. NOX4 inhibition potentiates immunotherapy by overcoming cancer-associated fibroblastmediated CD8 T-cell exclusion from tumors. Cancer Res 2020;80:1846-60. DOI PubMed

100. Huang H, Zhang Y, Gallegos V, et al. Targeting TGFbetaR2-mutant tumors exposes vulnerabilities to stromal TGFbeta blockade in pancreatic cancer. EMBO Mol Med 2019;11:e10515. DOI PubMed PMC

101. Feng R, Morine Y, Ikemoto T, et al. Nab-paclitaxel interrupts cancer-stromal interaction through C-X-C motif chemokine 10mediated interleukin-6 downregulation in vitro. Cancer Sci 2018;109:2509-19. DOI PubMed PMC

102. Alvarez R, Musteanu M, Garcia-Garcia E, et al. Stromal disrupting effects of nab-paclitaxel in pancreatic cancer. Br J Cancer 2013;109:926-33. DOI PubMed PMC

103. Mace TA, Shakya R, Pitarresi JR, et al. IL-6 and PD-L1 antibody blockade combination therapy reduces tumour progression in murine models of pancreatic cancer. Gut 2018;67:320-32. DOI PubMed PMC

104. Angevin E, Tabernero J, Elez E, et al. A phase I/II, multiple-dose, dose-escalation study of siltuximab, an anti-interleukin-6 monoclonal antibody, in patients with advanced solid tumors. Clin Cancer Res 2014;20:2192-204. DOI PubMed

105. US National Library of Medicine. Siltuximab and spartalizumab in patients with metastatic pancreatic cancer. Available from: https://clinicaltrials.gov/ct2/show/NCT04191421. [Last accessed on 8 Jun 2021].

106. US National Library of Medicine. Study of nab-paclitaxel and gemcitabine with or without tocilizumab in pancreatic cancer patients 
(PACTO). Available from: https://clinicaltrials.gov/ct2/show/NCT02767557. [Last accessed on 8 Jun 2021].

107. Bressy C, Lac S, Nigri J, et al. LIF drives neural remodeling in pancreatic cancer and offers a new candidate biomarker. Cancer Res 2018;78:909-21. DOI PubMed

108. Wang MT, Fer N, Galeas J, et al. Blockade of leukemia inhibitory factor as a therapeutic approach to KRAS driven pancreatic cancer. Nat Commun 2019;10:3055. DOI PubMed PMC

109. Shi Y, Gao W, Lytle NK, et al. Targeting LIF-mediated paracrine interaction for pancreatic cancer therapy and monitoring. Nature 2019;569:131-5. DOI PubMed PMC

110. Biffi G, Oni TE, Spielman B, et al. IL1-Induced JAK/STAT signaling is antagonized by TGFbeta to shape CAF heterogeneity in pancreatic ductal adenocarcinoma. Cancer Discov 2019;9:282-301. DOI PubMed PMC

111. Gore J, Craven KE, Wilson JL, et al. TCGA data and patient-derived orthotopic xenografts highlight pancreatic cancer-associated angiogenesis. Oncotarget 2015;6:7504-21. DOI PubMed PMC

112. Hurwitz H, Van Cutsem E, Bendell J, et al. Ruxolitinib + capecitabine in advanced/metastatic pancreatic cancer after disease progression/intolerance to first-line therapy: JANUS 1 and 2 randomized phase III studies. Invest New Drugs 2018;36:683-95. DOI PubMed PMC

113. Hurwitz HI, Uppal N, Wagner SA, et al. Randomized, double-blind, phase II study of ruxolitinib or placebo in combination with capecitabine in patients with metastatic pancreatic cancer for whom therapy with gemcitabine has failed. J Clin Oncol 2015;33:403947. DOI PubMed PMC

114. Whiteley A, Becerra C, McCollum D, et al. A pilot, non-randomized evaluation of the safety of anakinra plus FOLFIRINOX in metastatic pancreatic ductal adenocarcinoma patients. JCO 2016;34:e15750. DOI

115. Djurec M, Grana O, Lee A, et al. Saa3 is a key mediator of the protumorigenic properties of cancer-associated fibroblasts in pancreatic tumors. Proc Natl Acad Sci USA 2018;115:E1147-56. DOI PubMed PMC

116. Humbert M, Casteran N, Letard S, et al. Masitinib combined with standard gemcitabine chemotherapy: in vitro and in vivo studies in human pancreatic tumour cell lines and ectopic mouse model. PLoS One 2010;5:e9430. DOI PubMed PMC

117. Mitry E, Hammel P, Deplanque G, et al. Safety and activity of masitinib in combination with gemcitabine in patients with advanced pancreatic cancer. Cancer Chemother Pharmacol 2010;66:395-403. DOI PubMed

118. Deplanque G, Demarchi M, Hebbar M, et al. A randomized, placebo-controlled phase III trial of masitinib plus gemcitabine in the treatment of advanced pancreatic cancer. Ann Oncol 2015;26:1194-200. DOI PubMed PMC

119. US National Library of Medicine. A study of nab-paclitaxel and gemcitabine with or without olaratumab (LY3012207) in participants with metastatic pancreatic cancer. Available from: https://clinicaltrials.gov/ct2/show/NCT03086369. [Last accessed on 8 Jun 2021].

120. Waghray M, Yalamanchili M, Dziubinski M, et al. GM-CSF mediates mesenchymal-epithelial cross-talk in pancreatic cancer. Cancer Discov 2016;6:886-99. DOI PubMed PMC

121. Arlauckas SP, Garris CS, Kohler RH, et al. In vivo imaging reveals a tumor-associated macrophage-mediated resistance pathway in anti-PD-1 therapy. Sci Transl Med 2017;9:aal3604. DOI PubMed PMC

122. Lewis CE, Pollard JW. Distinct role of macrophages in different tumor microenvironments. Cancer Res 2006;66:605-12. DOI PubMed

123. Kitamura T, Qian BZ, Pollard JW. Immune cell promotion of metastasis. Nat Rev Immunol 2015;15:73-86. DOI PubMed PMC

124. Carleton M, Powers J, Phillips P, et al. Pharmacodynamics (PD) and genomic profiling of pts treated with cabiralizumab (cabira) + nivolumab (NIVO) provide evidence of on-target tumor immune modulations and support future clinical applications. JCO 2018;36:3020. DOI

125. Wainberg Z, Piha-Paul S, Luke J, et al. 32nd annual meeting and pre-conference programs of the society for immunotherapy of cancer (SITC 2017): late-breaking abstracts. J Immunother Cancer 2017;5:89.

126. Wang-Gillam A, O'Reilly EM, Bendell JC, et al. A randomized phase II study of cabiralizumab (cabira) + nivolumab (nivo) \pm chemotherapy (chemo) in advanced pancreatic ductal adenocarcinoma (PDAC). JCO 2019;37:TPS465. DOI

127. US National Library of Medicine. A study of cabiralizumab given with nivolumab with and without chemotherapy in patients with advanced pancreatic cancer. Available from: https://clinicaltrials.gov/ct2/show/NCT03336216. [Last accessed on 8 Jun 2021].

128. Razak AR, Cleary JM, Moreno V, et al. Safety and efficacy of AMG 820, an anti-colony-stimulating factor 1 receptor antibody, in combination with pembrolizumab in adults with advanced solid tumors. J Immunother Cancer 2020;8:e01006. DOI PubMed PMC

129. Sanford DE, Belt BA, Panni RZ, et al. Inflammatory monocyte mobilization decreases patient survival in pancreatic cancer: a role for targeting the CCL2/CCR2 axis. Clin Cancer Res 2013;19:3404-15. DOI PubMed PMC

130. Mitchem JB, Brennan DJ, Knolhoff BL, et al. Targeting tumor-infiltrating macrophages decreases tumor-initiating cells, relieves immunosuppression, and improves chemotherapeutic responses. Cancer Res 2013;73:1128-41. DOI PubMed PMC

131. Noel M, O'Reilly EM, Wolpin BM, et al. Phase $1 \mathrm{~b}$ study of a small molecule antagonist of human chemokine (C-C motif) receptor 2 (PF-04136309) in combination with nab-paclitaxel/gemcitabine in first-line treatment of metastatic pancreatic ductal adenocarcinoma. Invest New Drugs 2020;38:800-11. DOI PubMed PMC

132. Linehan D, Noel MS, Hezel AF, et al. Overall survival in a trial of orally administered CCR2 inhibitor CCX872 in locally advanced/metastatic pancreatic cancer: correlation with blood monocyte counts. JCO 2018;36:92. DOI

133. Nywening TM, Wang-Gillam A, Sanford DE, et al. Targeting tumour-associated macrophages with CCR2 inhibition in combination with FOLFIRINOX in patients with borderline resectable and locally advanced pancreatic cancer: a single-centre, open-label, dosefinding, non-randomised, phase $1 \mathrm{~b}$ trial. Lancet Oncol 2016;17:651-62. DOI PubMed PMC

134. Janson C, Jung H, Ertl L, et al. Abstract 5655: inhibition of CCR2 potentiates checkpoint inhibitor immunotherapy in murine model of pancreatic cancer. Cancer Res 2017;77:5655. DOI 
135. Kwon S, Munroe X, Crawley SC, et al. Expression of connective tissue growth factor in pancreatic cancer cell lines. Int J Oncol 2007;31:693-703. PubMed

136. Picozzi VJ, Rocha FG, Helton S, et al. Randomized, open-label trial of gemcitabine/nab-paclitaxel (G/NP) $\pm F G-3019$ as neoadjuvant chemotherapy in locally advanced, unresectable pancreatic cancer (LAPC). JCO 2016;34:457. DOI

137. US National Library of Medicine. Evaluation of efficacy and safety of neoadjuvant treatment with pamrevlumab in combination with chemotherapy (either gemcitabine plus nab-paclitaxel or FOLFIRINOX) in locally advanced pancreatic cancer. Available from: https://clinicaltrials.gov/ct2/show/NCT03941093. [Last accessed on 8 Jun 2021].

138. Kessenbrock K, Plaks V, Werb Z. Matrix metalloproteinases: regulators of the tumor microenvironment. Cell 2010;14:52-67. DOI PubMed PMC

139. Moore MJ, Hamm J, Dancey J, et al. Comparison of gemcitabine versus the matrix metalloproteinase inhibitor BAY $12-9566$ in patients with advanced or metastatic adenocarcinoma of the pancreas: a phase III trial of the National Cancer Institute of Canada Clinical Trials Group. J Clin Oncol 2003;21:3296-302. DOI PubMed

140. Evans JD, Stark A, Johnson CD, et al. A phase II trial of marimastat in advanced pancreatic cancer. Br J Cancer 2001;85:1865-70. DOI PubMed PMC

141. Bramhall SR, Schulz J, Nemunaitis J, et al. A double-blind placebo-controlled, randomised study comparing gemcitabine and marimastat with gemcitabine and placebo as first line therapy in patients with advanced pancreatic cancer. Br J Cancer 2002;87:1617. DOI PubMed PMC

142. Bendell J, Sharma S, Patel MR, et al. Safety and efficacy of andecaliximab (GS-5745) plus gemcitabine and nab-paclitaxel in patients with advanced pancreatic adenocarcinoma: results from a phase I study. Oncologist 2020;25:954-62. DOI PubMed PMC

143. Shah MA, Yanez Ruiz EP, Bodoky G, et al. A phase III, randomized, double-blind, placebo-controlled study to evaluate the efficacy and safety of andecaliximab combined with mFOLFOX6 as first-line treatment in patients with advanced gastric or gastroesophageal junction adenocarcinoma (GAMMA-1). JCO 2019;37:4. DOI

144. Zhou H, Roy S, Cochran E, et al. M402, a novel heparan sulfate mimetic, targets multiple pathways implicated in tumor progression and metastasis. PLoS One 2011;6:e21106. DOI PubMed PMC

145. Niu Q, Wang W, Li Y, et al. Low molecular weight heparin ablates lung cancer cisplatin-resistance by inducing proteasome-mediated ABCG2 protein degradation. PLoS One 2012;7:e41035. DOI PubMed PMC

146. Franchini M, Mannucci PM. Low-molecular-weight heparins and cancer: focus on antitumoral effect. Ann Med 2015;47:116-21. DOI PubMed

147. O'Reilly EM, Roach J, Miller P, et al. Safety, pharmacokinetics, pharmacodynamics, and antitumor activity of necuparanib combined with nab-paclitaxel and gemcitabine in patients with metastatic pancreatic cancer: phase I results. Oncologist 2017;22:1429-e139. DOI PubMed PMC

148. O'Reilly EM, Barone D, Mahalingam D, et al. Randomised phase II trial of gemcitabine and nab-paclitaxel with necuparanib or placebo in untreated metastatic pancreas ductal adenocarcinoma. Eur J Cancer 2020;132:112-21. DOI PubMed PMC

149. Gunderson AJ, Kaneda MM, Tsujikawa T, et al. Bruton tyrosine kinase-dependent immune cell cross-talk drives pancreas cancer. Cancer Discov 2016;6:270-85. DOI PubMed PMC

150. Tempero M, Oh D, Macarulla T, et al. Ibrutinib in combination with nab-paclitaxel and gemcitabine as first-line treatment for patients with metastatic pancreatic adenocarcinoma: results from the phase 3 RESOLVE study. Ann Oncol 2019;30:iv126. DOI

151. Masso-Valles D, Jauset T, Serrano E, et al. Ibrutinib exerts potent antifibrotic and antitumor activities in mouse models of pancreatic adenocarcinoma. Cancer Res 2015;75:1675-81. DOI PubMed PMC

152. George AJ, Thomas WG, Hannan RD. The renin-angiotensin system and cancer: old dog, new tricks. Nat Rev Cancer 2010;10:74559. DOI PubMed

153. Diop-Frimpong B, Chauhan VP, Krane S, et al. Losartan inhibits collagen I synthesis and improves the distribution and efficacy of nanotherapeutics in tumors. Proc Natl Acad Sci USA 2011;108:2909-14. DOI PubMed PMC

154. Chauhan VP, Martin JD, Liu H, et al. Angiotensin inhibition enhances drug delivery and potentiates chemotherapy by decompressing tumour blood vessels. Nat Commun 2013;4:2516. DOI PubMed PMC

155. Murphy JE, Wo JY, Ryan DP, et al. Total neoadjuvant therapy with FOLFIRINOX in combination with Losartan followed by chemoradiotherapy for locally advanced pancreatic cancer: a phase 2 clinical trial. JAMA Oncol 2019;5:1020-7. DOI PubMed PMC

156. Liu H, Naxerova K, Pinter M, et al. Use of angiotensin system inhibitors is associated with immune activation and longer survival in nonmetastatic pancreatic ductal adenocarcinoma. Clin Cancer Res 2017;23:5959-69. DOI PubMed PMC

157. Sherman MH, Yu RT, Engle DD, et al. Vitamin D receptor-mediated stromal reprogramming suppresses pancreatitis and enhances pancreatic cancer therapy. Cell 2014;159:80-93. DOI PubMed PMC

158. Borazanci EH, Jameson G, Korn RL, et al. Abstract CT152: A Phase II pilot trial of nivolumab (N) + albumin bound paclitaxel (AP) + paricalcitol $(\mathrm{P})+$ cisplatin $(\mathrm{C})+$ gemcitabine $(\mathrm{G})(\mathrm{NAPPCG})$ in patients with previously untreated metastatic pancreatic ductal adenocarcinoma (PDAC). Cancer Res 2019;79:CT152. DOI

159. US National Library of Medicine. Combination therapy for patients with untreated metastatic pancreatic ductal adenocarcinoma. Available from: https://www.clinicaltrials.gov/ct2/show/NCT02754726. [Last accessed on 8 Jun 2021].

160. Chung VM, Borazanci EH, Jameson GS, et al. A SU2C catalyst randomized phase II trial of pembrolizumab with or without paricalcitol in patients with stage IV pancreatic cancer who have been placed in best possible response. JCO 2018;36:TPS4154. DOI

161. US National Library of Medicine. A SU2C Catalyst $₫$ trial of a PD1 inhibitor with or without a vitamin $\mathrm{D}$ analog for the maintenance of pancreatic cancer. Available from: https://clinicaltrials.gov/ct2/show/NCT03331562. [Last accessed on 8 Jun 2021].

162. Carapuca EF, Gemenetzidis E, Feig C, et al. Anti-stromal treatment together with chemotherapy targets multiple signalling pathways 
in pancreatic adenocarcinoma. $J$ Pathol 2016;239:286-96. DOI PubMed PMC

163. US National Library of Medicine. Phase IIb randomised trial of ATRA in a novel drug combination for pancreatic cancer (STARPAC2). Available from: https://clinicaltrials.gov/ct2/show/NCT04241276. [Last accessed on 8 Jun 2021].

164. US National Library of Medicine. Olaptesed (NOX-A12) alone and in combination with pembrolizumab in colorectal and pancreatic cancer (Keynote-559). Available from: https:/www.clinicaltrials.gov/ct2/show/NCT03168139. [Last accessed on 8 Jun 2021].

165. US National Library of Medicine. L-DOS47 plus doxorubicin in advanced pancreatic cancer. Available from: https://clinicaltrials.gov/ct2/show/NCT04203641. [Last accessed on 8 Jun 2021].

166. US National Library of Medicine. Defactinib combined with pembrolizumab and gemcitabine in patients with advanced cancer. Available from: https://clinicaltrials.gov/ct2/show/NCT02546531. [Last accessed on 8 Jun 2021].

167. Wang-Gillam A, Lockhart AC, Tan BR, et al. Phase I study of defactinib combined with pembrolizumab and gemcitabine in patients with advanced cancer. JCO 2018;36:380. DOI

168. Wang-Gillam A, McWilliams R, Lockhart AC, et al. Abstract CT118: Phase I study of defactinib combined with pembrolizumab and gemcitabine in patients with advanced cancer: experiences of pancreatic ductal adenocarcinoma (PDAC) patients. Cancer Res 2020;80:CT118. DOI

169. US National Library of Medicine. A phase 1B study of canakinumab, spartalizumab, nab-paclitaxel, and gemcitabine in metastatic PC patients (PanCAN-SR1). Available from: https://clinicaltrials.gov/ct2/show/NCT04581343. [Last accessed on 8 Jun 2021]. 